\title{
Lunar Rhythmicities in the Biology of Trees, Especially in the Germination of European Spruce (Picea abies Karst.): A New Statistical Analysis of Previously Published Data
}

\author{
Ernst Zürcher ${ }^{1} \&$ Rodolphe Schlaepfer ${ }^{2}$ \\ ${ }^{1}$ Department of Architecture, Wood and Civil Engineering, Bern University of Applied Sciences, Switzerland \\ ${ }^{2}$ Laboratory of Ecological Systems (ECOS), Swiss Federal Institute of Technology Lausanne EPFL - ENAC - \\ IIE, Ch-1015 Lausanne, Switzerland \\ Correspondence: Ernst Zürcher, Department of Architecture, Wood and Civil Engineering, Bern University of \\ Applied Sciences, Switzerland. E-mail: ernst.zuercher@bfh.ch
}

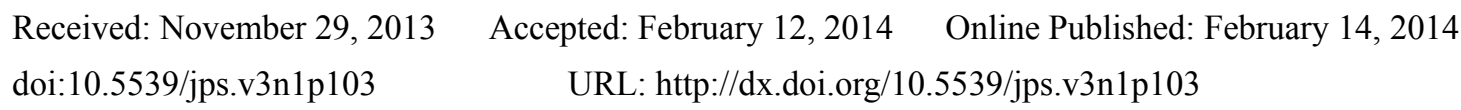

\begin{abstract}
Interest in the question of moon-related fluctuations in tree biology and physiology has been revived by recent experimental research, which could confirm the existence of real phenomena. In this context, previously published extensive data from germination tests on European Spruce using established standard devices, which appeared at the time to give negative results, has been analysed with the help of modern statistical tools. Slight but statistically significant lunar rhythmicities were revealed by this new analysis. One of these fluctuations is found in the germination rate from sowings shortly before Full Moon, compared to those shortly before New Moon.
\end{abstract}

Keywords: chronobiology, germination, spruce, lunar rhythms, synodic moon

\section{Introduction}

The idea of a relationship between plant growth and moon cycles has often been considered by scientists as simply old superstition. Nevertheless, an interesting corpus of well documented experimental work exists and suggests objective phenomena interacting at different levels. An extensive review of the available data and interpretations has recently been published (Zürcher, 2008, 2011), based on a series of 88 scientific publications related to this topic. One of the basic modern references in this context gives an overview of studies according to scientific criteria, dealing with rhythms in plant and animal biology linked to lunar periodicities (Endres \& Schad, 1997).

Since we started working experimentally on the field of tree chronobiology linked to lunar rhythms, it has been possible to observe significant relationships for different aspects of tree life and wood properties. Here is a short overview:

- The germination and initial growth of some tropical trees show a decided rhythmic character. Speed of germination, percent of germination, average height, and maximum height of Musizi (Maesopsis eminii, a Rhamnaceae) after 4 months are systematically related to the timing of sowing in relation to the moon phase (Zürcher, 1992, 2000). These results are coherent with the first published findings in this field made by L. Kolisko on cereal, vegetable and floral species (Kolisko, 1927, 1929, 1934, 1935).

- An interdisciplinary reworking of previously published, long-term tree-physiological research results (variations of tree diameters obtained by extensometry) has enabled researchers to consider an unexpected aspect. For Spruce trees (Picea abies) held under constant conditions (greenhouse, darkness), it could be established that the synodic moon-rhythm at a daily level (gravimetric tide-rhythm and periods) modulates the diameter fluctuations (Zürcher, Cantiani, Sorbetti-Guerri, \& Michel, 1998).

- Data of trees measured in open conditions, reanalyzed recently with more sophisticated tools, brought spectacular confirmation of the role of lunar tides in tree physiology of this and further species (Barlow, Mikulecky, \& Strestik, 2010). Moreover, it was possible to detect the same type of fluctuations by measuring with a 
high-sensitivity device the low-potential electric currents along the trees' stems, depending on the physiological phase of the trees (Holzknecht, 2002; Holzknecht \& Zürcher, 2006).

- The drying behavior (water loss and shrinkage) and the final density of wood systematically and coherently vary according to the tree felling date, if analyzed in relation to the season and to the position of the moon. The observed fluctuations are yet more complex than mentioned in forestry traditions existing all over the world (Zürcher \& Mandallaz, 2001; Zürcher, Schlaepfer, Conedera, \& Giudici, 2010). In addition, after drying of the test samples, a simultaneous moon-related fluctuation in the hygroscopicity, compression strength and calorific value per volume unit is still observed (Zürcher, Rogenmoser, Kartalaei, \& Rambert, 2012).

Concerning the last mentioned research field, it is known that traditional knowledge and practices concerning agricultural and forestry activities - so-called rural rules - are still widespread in various cultures on different continents. Among them, rules exist about effects of the tree-felling date on the properties of wood (Hauser, 1973; Broendegaard, 1985; Cole \& Balik, 2010). The first written evidence of this knowledge dates back to Theophrastus of Eresos (372-287 BC), who in his History of Plants (V, 1, 3) states that there is an appropriate season for cutting the trees and - within the season - if cutting at the beginning of the waning moon, the wood is harder and less likely to rot. This popular knowledge has been passed down to our times and to the local practices of felling trees during different moon positions depending on the specific forms of wood utilization (Zürcher, 2000). Despite such a broad and ancient tradition of referring to the moon phases for determining the most suitable date for agricultural (e.g. seeding) and forestry (e.g. tree-felling) activities, there is relatively little scientific research on this topic.

In wood physics, the wood-water relations have been extensively studied (Skaar, 1988; Navi \& Heger, 2005), but not yet including "time" as a possible initial, rhythmic factor of variation in the sample properties; the role of this factor appears at present mainly in the sorption hysteresis and in the viscoelastic behavior. Two publications can nevertheless be cited in relation to the apparently fluctuating plant-water relations at issue, where the time factor "Moon" plays an essential role in living plants, especially their germinating behavior. Experimentally-based, large scale studies with Bean seeds (Phaseolus vulgaris), a dormant reproductive material, demonstrated a spectacular lunar-cycle-dependent water uptake during immersion (Brown \& Chow, 1973, who tested 7931 series of 20 seeds; Spruyt, Verbelen \& De Greef, 1987, after a trial during 25 lunations). Short term fluctuations with a period of a lunar week (7.4 days) had a relative amplitude of up to $20 \%$ in the tested series of Brown et al. (1973), and of up to $13 \%$ in the series of Spruyt et al. (1987).

A recent, promising new way of interpreting these phenomena at the physical-chemical level is given in Pollack (2013), who introduces the concept of a fourth phase of water, between liquid and solid, appearing near hydrophilic membranes or surfaces. Pollack's work is elaborated on the basis of own experiments and with integration of the observations of many other researchers, including the results of G. Piccardi (1962) and V. Voeikov (presented in Pollack, 2013). These researchers observed lunar fluctuations in the properties of water when studying chemical precipitations or light emissions from aequeous solutions.

The scope of the present contribution is to bring a new element into the field of lunar chronobiology of trees, on the basis of extensive, previously published experimental data from germination tests, in which a significant moon-related fluctuation had been overlooked for decades.

\section{The Synodic Lunar Rhythm and Its Sub-Divisions}

The principal lunar cycle, the synodic one, is determined by the relative movement of Earth, Sun and Moon, the time required for our satellite to complete a full phase from New Moon (NM) to the next New Moon being 29.53 days (Figure 1). It can be divided into sub-cycles linked to the phenomenon of the tides, due to the daily rotation of the Earth. The following can be distinguished:

\begin{tabular}{lll}
\hline Period & Rhythm or Lunar Cycle & Unit \\
\hline 12.42 hours & Tidal or lunitidal & Twice-daily tide \\
{$[24.0$ hours } & Daily & Day: solar cycle, reference] \\
24.85 hours & Tidal day, lunidian & Lunar day \\
7.38 days & Circaseptan & Lunar week \\
14.76 days & Semi-lunar & Syzygy (conjunction or opposition in relation to the sun) \\
29.53 days & Lunar, synodic & Lunation, lunar month \\
\hline
\end{tabular}




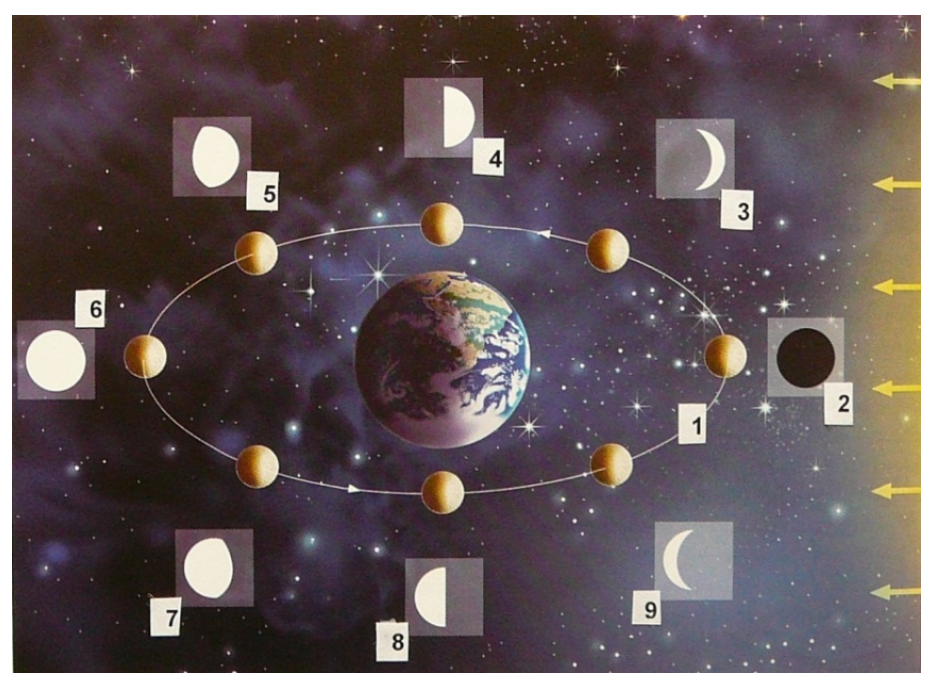

Figure 1. The phases of the Moon (corresponding to the synodic rhythm, with a revolution in 29.53 days)

1) Lunar orbit around the Earth, for an observer looking at the Earth-Moon system from a long way above the Earth's North Pole; 2) New Moon [NM], observed from the Earth; 3) Waxing crescent [after New Moon, aNM]; 4) First quarter [1stQ]; 5) Waxing gibbous [before Full Moon, bFM]; 6) Full Moon [FM]; 7) Waning gibbous [after Full Moon, aFM]; 8) Last quarter [3rdQ]; 9) Waning crescent [before New Moon, bNM]. The arrows on the right side represent the solar rays.

\section{Germination and Initial Growth in Trees}

Some details about the first field of research mentioned in the introduction: A tree nursery situated in the tropics, in Rwanda, offered interesting conditions for experiments on the germination and initial growth of woody species according to the moon factor, since temperatures and day-lengths were less variable than in higher latitudes, and the dry seasons could be compensated by watering. The work occurred over 3 years: a preliminary trial, a simple main trial with 12 sowings of 4 repetitions of 50 seeds, then a control and complementary trial. The sowings of the main trial were carried out 2 days before the full moon, alternating with sowings 2 days before the new moon, as suggested by Kolisko's work mentioned above.

For African Musizi (Maesopsis eminii, Rhamnaceae) found from Liberia to Kenya, the speed and rate of germination and the mean and maximum values of growth in the first months, vary in a clearly rhythmic manner, with superior values for sowings just before the full moon (Zürcher, 1992).

An independent trial carried out 5 years later in West Africa using the same method on 4 dryland species, Sclerocarya birrea (Anacardiaceae), Adansonia digitata (Bombacaceae), Afzelia africana (Caesalpiniaceae) and Detarium microcarpum (Fabaceae), confirms this rhythmic character, but essentially for the development stage 2 months after sowing (Bagnoud, 1995).

It is important in this type of trial to choose the date with great precision, for near the favorable moments between the first quarter and the full moon, the exact moment of the full moon gives results sometimes lower than those of 2 days before the new moon for Musizi, which agrees with Milton's observations on the development of corn coleoptile (Milton, 1974). It is important, however, to avoid oversimplifying this relation between plant rhythms and lunar cycles. Indeed, certain species can show the opposite behavior and respond positively to a sowing before the new moon, such as Black wattle (Acacia melanoxylon, Fabaceae) and Sesban/Egyptian pea (Sesbania sesban, Fabaceae), a behaviour that brings to mind that of the potato observed by Popp (1933), and later by Spiess (1994). These first positive results concerning forest species demonstrate nonetheless the importance that lunar chronobiology may have for operating tree nurseries seeking to produce vigorous trees.

\section{A Trial Revisited}

In his short review of research on lunar rhythms in the plant world, Beeson (1946) bases his generally sceptical opinion on the extensive work of Rohmeder (1938), carried out with a visibly very critical prejudice against "moon superstition". This work aimed to test the phenomena which had recently been revealed by L. Kolisko. 
Through extremely exhaustive laboratory trials lasting from 1927 to 1935, Kolisko had demonstrated the variations in growth of plants according to the lunar synodic rhythm. The seeds of vegetable, floral, and cereal species (lettuce [Lactuca sativa], white cabbage [Brassica oleracea], leek [Allium porrum], tomato [Lycopersicon esculentum], pea [Pisum sativum], common bean [Phaseolus vulgaris], lovage [Levisticum officinale], yarrow [Achillea millefolium], lemon balm [Melissa officinalis], monkshood [Aconitum napellus], corn [Zea mays], wheat [Triticum spp.], oats [Avena sativa], barley [Hordeum vulgare]) sown 2 days before the full moon showed better germination and stronger growth, formed more numerous inflorescences, and produced a better harvest than the seeds sown 2 days before the new moon. Some experimental series showed an abrupt change between the ideal period, about 2 days before the full moon, and the exact day of the full moon, which reveals a form of phase difference between the visible course of our satellite and its effect on germination. Kolisko had worked with very homogeneous material and followed for the choice of dates the suggestions of Rudolf Steiner, founder of the bio-dynamic agriculture method, practiced since with increasing success for more than 80 years.

Rohmeder's experiments at the Laboratory of the Forest Seed Testing Station in Munich were carried out meticulously with a stock of Spruce seeds having a medium germination power and uniform quality, during 1936 (4 months) and 1937 (7 months), consisting of 87 series of 1200 seeds, or a total of 104'400 seeds, whose speed and rate of germination were determined after 7, 10, 14 and 21 days. For these tests, 4 different laboratory germination devices were used simultaneously - the 3 best systems being retained for results interpretation (based on 87 series of 900 seeds, or a total of 78'300 seeds). The retained systems were a) the well-established "Jacobsen germination device", working with light, controlled temperature changes (specific to Spruce) and controlled humidity of the filter-paper sheets bearing the seed, b) the "Rodewald germination device ", similar to Jacobsen but using wet sand and c) a dark chamber with a constant temperature of $20^{\circ} \mathrm{C}$. The fourth device, an incubator with a constant temperature of $25^{\circ} \mathrm{C}$, gave results too irregular to be included. Eight dates per synodic lunar month were chosen for sowing: $1^{\text {st }}$ quarter, full moon, last quarter, new moon, plus waxing crescent, waxing gibbous, waning gibbous and waning crescent (see Figure 1). The data were collected in ad-hoc form, after having checked the anatomy of the non-germinated single seeds. Table 1 and Table 2 show the germination rates as mean values from 3 series of 100 seeds per device after 21 days, as published by E. Rohmeder (1938). The variations having occurred each year within a relatively narrow range, the effect of seed ageing during the long series in 1937 having been stronger than the "moon" effect and the curves representing germination rate relative to lunar sowing date having presented sometimes divergent paths, all this brought the author, without any statistical analysis (not commonly used at the time?) to the definitive conclusion that these trials "provide no argument indicating that the change in lunar phases might influence the germination of Spruce seeds".

Table 1. Germination results 1936 (July to October), as mean values in \%, from 3 germination test devices

\begin{tabular}{cccccc}
\hline Moon phase & 1.7. to 27.7. & 31.7. to 25.8. & 29.8. to 23.9. & 26.9. to 23.10. & Mean \\
\hline & 75 & 71 & 73 & 70 & 72.2 \\
& 72 & 69 & 68 & 74 & 70.8 \\
& 74 & 72 & 70 & 71 & 71.7 \\
& 77 & 75 & 76 & 72 & 75.0 \\
& 73 & 70 & 70 & 70 & 70.7 \\
& 71 & 73 & 71 & 75 & 72.5 \\
& 71 & 72 & 70 & 68 & 70.3 \\
& 74 & 72 & 64 & 73 & 70.7 \\
Overall average & 73.4 & 71.7 & 70.3 & 71.6 & 71.7 \\
\hline
\end{tabular}

Table 1 shows the germination data presented in Rohmeder (1938) for the year 1936 (4 months), obtained with 3 
germination devices used simultaneously. Each value represents the mean germination rate out of 900 seeds. During each month, 8 sowings occurred according to the moon phases (symbols on the left side: $\circ=$ full moon / $\bullet=$ new moon).

Table 2. Germination results 1937 (January to August), as mean values in \%, from 3 germination test devices

\begin{tabular}{|c|c|c|c|c|c|c|c|c|}
\hline $\begin{array}{l}\text { Moon } \\
\text { phase }\end{array}$ & $\begin{array}{c}\text { 22.1. to } \\
18.2 \text {. }\end{array}$ & $\begin{array}{c}\text { 22.2. to } \\
19.3 \text {. }\end{array}$ & $\begin{array}{c}\text { 23.3. to } \\
17.4 \text {. }\end{array}$ & $\begin{array}{c}\text { 21.4. to } \\
18.5 \text {. }\end{array}$ & $\begin{array}{c}\text { 21.5. to } \\
15.6 \text {. }\end{array}$ & $\begin{array}{c}\text { 18.6. to } \\
15.7 \text {. }\end{array}$ & $\begin{array}{c}\text { 19.7. to } \\
14.8 \text {. }\end{array}$ & Mean \\
\hline & 83 & 83 & 81 & 77 & 82 & 79 & 76 & 80.1 \\
\hline & 80 & 80 & 79 & 79 & 77 & 75 & 76 & 78.0 \\
\hline & 77 & 81 & 82 & 82 & 76 & 80 & 77 & 79.2 \\
\hline & 80 & 77 & 77 & 79 & 75 & 81 & 75 & 77.7 \\
\hline & 80 & 83 & 79 & 76 & 74 & - & 75 & 77.8 \\
\hline & 81 & 80 & 80 & 80 & 77 & 76 & 77 & 78.7 \\
\hline & 80 & 82 & 80 & 76 & 73 & 77 & 72 & 77.1 \\
\hline & 73 & 79 & 81 & 79 & 77 & 76 & 74 & 77.7 \\
\hline $\begin{array}{l}\text { Overall } \\
\text { average }\end{array}$ & 79.9 & 80.6 & 79.9 & 78.5 & 78.4 & 77.7 & 75.3 & 78.3 \\
\hline
\end{tabular}

Table 2 shows the germination data presented in Rohmeder (1938) for the year 1937 (7 months), obtained with 3 germination devices used simultaneously. Each value represents the mean germination rate out of 900 seeds. During each month, 8 sowings occurred according to the moon phases (symbols on the left side: $\circ=$ full moon / - = new moon).

If we apply today, 76 years later, a statistical analysis of variance for the cumulative data from the 2 periods of trials (Table 1 and Table 2), we obtain for the variations in germination rate about its general monthly mean a range which is indeed narrow, but comprising clearly significant differences. The preliminary steps to this analysis were to create a new table with the months as lines and the lunar-related sowings as vertical rows, putting together the values of 1936 and of 1937 (Table 3A). One missing value due to illness of the laboratory operator $\left(5^{\text {th }}\right.$ July 1937 , bNM) had to be interpolated by attribution of the current monthly mean value. In order to normalize the values originating from the two successive series and to neutralize the ageing phenomenon of the seeds, the variations around each monthly mean value $(\rightarrow 100 \%)$ have been calculated (Table 3B).

In Table 3, the original data are presented in two steps: A) Data from Table 1 and Table 2 in a new distribution, with months (from 1936 and 1937) in lines and moon phases in columns. Interpolation of a missing value (bNM, July1937). B) Variations of the values around the current monthly average, expressed in percent (in order to eliminate the ageing effect). FM: full moon / NM: new moon / 1stQ: first quarter / 3rdQ: third quarter / bFM: 3 days before full moon / aFM: 3 days after full moon / bNM: 3 days before new moon / aNM: 3 days after new moon. The numbers 2-9 correspond to Figure 1 . In place of the missing value of $5^{\text {th }}$ July 1937 , we introduced in Table 1A the whole number (78) nearest to the average of the current month (77.7). 
Table 3A. Germination rates (in \%) from moon-related successive sowings in 1936 and 1937 (sowings July to October 1936 + January 1937 to August 1937

\begin{tabular}{cccccccccc}
\hline$\rightarrow$ & 5 & 6 & 7 & 8 & 9 & 2 & 3 & 4 & \\
Synodic periods & bFM & FM & aFM & 3rdQ & bNM & NM & aNM & 1 stQ & Mean values \\
\hline $1.7-27.7 .1936$ & 75 & 72 & 74 & 77 & 73 & 71 & 71 & 74 & 73.4 \\
$31.7-25.8$ & 71 & 69 & 72 & 75 & 70 & 73 & 72 & 72 & 71.7 \\
$29.8-23.9$ & 73 & 68 & 70 & 76 & 70 & 71 & 70 & 64 & 70.3 \\
$26.9-23.10$ & 70 & 74 & 71 & 72 & 70 & 75 & 68 & 73 & 71.6 \\
$22.1-18.2 .37$ & 83 & 80 & 77 & 80 & 80 & 81 & 80 & 78 & 79.9 \\
$22.2-19.3$ & 83 & 80 & 81 & 77 & 83 & 80 & 82 & 79 & 80.6 \\
$23.3-17.4$ & 81 & 79 & 82 & 77 & 79 & 80 & 80 & 81 & 79.9 \\
$21.4-18.5$ & 77 & 79 & 82 & 79 & 76 & 80 & 76 & 79 & 78.5 \\
$21.5-15.6$ & 82 & 77 & 76 & 75 & 74 & 77 & 73 & 77 & 76.4 \\
$18.6-15.7$ & 79 & 75 & 80 & 81 & 78 & 76 & 77 & 76 & 77.7 \\
$19.7-14.8$ & 76 & 76 & 77 & 75 & 75 & 77 & 72 & 74 & 75.3 \\
\hline
\end{tabular}

Table 3B. Germination rate for the same periods and Moon phases, relatively to the current monthly average

\begin{tabular}{cccccccccc}
\hline$\rightarrow$ & 5 & 6 & 7 & 8 & 9 & 2 & 3 & 4 & \\
Synodic periods & bFM & FM & aFM & 3rdQ & bNM & NM & aNM & 1 stQ & Mean values \\
\hline $1.7-27.7 .1936$ & 102.2 & 98.1 & 100.8 & 104.9 & 99.5 & 96.7 & 96.7 & 100.8 & 100 \\
$31.7-25.8$ & 99 & 96.2 & 100.4 & 104.6 & 97.6 & 101.8 & 100.4 & 100.4 & 100.1 \\
$29.8-23.9$ & 103.8 & 96.7 & 99.6 & 108.1 & 99.6 & 101 & 99.6 & 91 & 99.9 \\
$26.9-23.10$ & 97.8 & 103.4 & 99.2 & 100.6 & 97.8 & 104.7 & 95 & 102 & 100 \\
$22.1-18.2 .37$ & 103.9 & 100.1 & 96.4 & 100.1 & 100.1 & 101.4 & 100.1 & 97.6 & 100 \\
$22.2-19.3$ & 103 & 99.3 & 100.5 & 95.5 & 103 & 99.3 & 101.7 & 98 & 100 \\
$23.3-17.4$ & 101.4 & 98.9 & 102.6 & 96.4 & 98.9 & 100.1 & 100.1 & 101.4 & 100 \\
$21.4-18.5$ & 98.1 & 100.6 & 104.5 & 100.6 & 96.8 & 101.9 & 96.8 & 100.6 & 100 \\
$21.5-15.6$ & 107.3 & 100.8 & 99.5 & 98.2 & 96.9 & 100.8 & 95.5 & 100.8 & 100 \\
$18.6-15.7$ & 101.7 & 96.5 & 103 & 104.2 & 100.4 & 97.8 & 99.1 & 97.8 & 100.1 \\
$19.7-14.8$ & 100.9 & 100.9 & 102.3 & 99.6 & 99.6 & 102.3 & 95.6 & 98.3 & 99.9 \\
Overall mean & 101.7 & 99.2 & 100.8 & 101.2 & 99.1 & 100.7 & 98.3 & 99 & \\
St. deviation & 2.8 & 2.2 & 2.2 & 3.9 & 1.8 & 2.2 & 2.4 & 3.1 & \\
\hline
\end{tabular}

\section{Statistical Analysis}

The analysis was performed with the help of the statistical tool " $R$ ", which is a free software environment for statistical computing and graphics. It compiles and runs on a wide variety of UNIX platforms, Windows and MacOS. R version 3.0.2 (released on 2013-09-25) was used.

\subsection{Boxplot [from the statistical software "Statistica"]}

The visual representation of the mean values from the germination tests performed in eight different lunar synodic phases is given with a general boxplot (Figure 2), featuring the means, their respective standard error SE, double standard deviation SD, outliers and extremes. The standard error SE is a measure of the precision of the estimated mean. It implies that, if the sampling were repeated a large number of times, the true value of the unknown mean would lie with a probability of roughly $68 \%$ within the range plus/minus SE. SD represents the standard deviation; the range plus/minus 2SD comprises, if the distribution is normal, roughly $95 \%$ of the 
observed single values. An overview of the exact mean values with their respective standard deviations is given in Table 4.

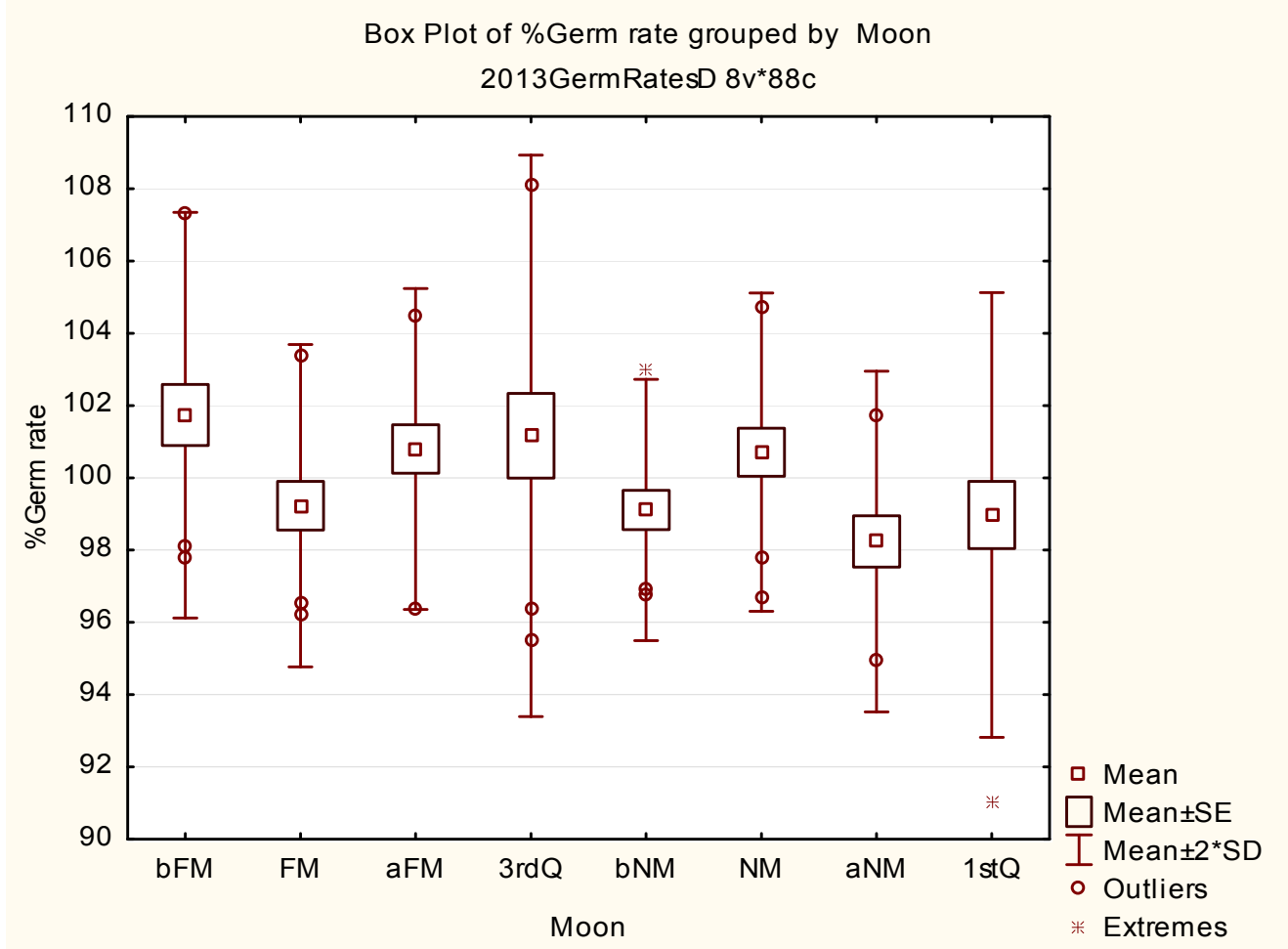

Figure 2. Boxplot of the germination rate in \%, relatively to the global mean of the current month, differentiated in eight lunar phases at the day of sowing

Table 4. Mean germination rates and their standard deviations for the 8 moon positions

\begin{tabular}{lllllllll}
\hline & bFM & FM & aFM & 3rdQ & bNM & NM & aNM & 1stQ \\
\hline Mean & 101.74 & 99.23 & 100.80 & 101.16 & 99.11 & 100.71 & 98.24 & 98.97 \\
St. dev. & 2.81 & 2.23 & 2.22 & 3.88 & 1.81 & 2.20 & 2.36 & 3.08 \\
\hline
\end{tabular}

The mean germination rates and their standard deviations are given here for the 8 Moon positions at the day of sowing. The largest difference is observed between bFM and aNM, representing 3.5\% .

\subsection{Overall Analysis of Variance}

Question: Is there an overall Moon effect on \% germination rate?

The corresponding statistical output 1 is as follows:

\begin{tabular}{|c|c|c|c|c|c|}
\hline & Df & Sum Sq & Mean Sq & $F$ value & $\operatorname{Pr}>F$ \\
\hline Moon & 7 & 121.75 & 17.3927 & 2.4846 & $0.02321 *$ \\
\hline Residuals & 80 & 560.02 & 7.0002 & & \\
\hline Signif. codes & $0:$ ‘***’ & 0.001: '**' & $0.01:$ '*’ & $0.05: '$. & $0.1:^{\prime}$, \\
\hline
\end{tabular}

Answer: There is a significant overall Moon effect $(\mathrm{p}=0.02321)$ on the germination rate. The Moon explains $11 \%$ of the total variation of the germination rate.

This answer leads to the following question: 
- Can we explain this overall Moon effect?

For this purpose, we can explore which contrasts between Moon positions are contributing to the overall Moon effect. In this sense, we formulate four subquestions, arranged from general to more specific (in relation to Full Moon and New Moon, the two reference phases appearing in traditional rules):

- Question a: Is the average germination rate before, at and after the FM different from the average germination rate before, at and after NM? This question can be tested with the contrast $\mathrm{c} 1$ $(1 / 3 \mathrm{bFM}+1 / 3 \mathrm{FM}+1 / 3 \mathrm{aFM}-1 / 3 \mathrm{bNM}-1 / 3 \mathrm{NM}-1 / 3 \mathrm{aNM})$

- Question b: Is the average germination rate before and after FM different from the germination rate at FM? This question can be tested with the contrast $\mathrm{c} 2(1 / 2 \mathrm{bFM}+1 / 2 \mathrm{aFM}-\mathrm{FM})$

- Question c: Is the average germination rate before and after NM different from the germination rate at NM? This question can be tested with the contrast $\mathrm{c} 3(1 / 2 \mathrm{bNM}+1 / 2 \mathrm{aNM}-\mathrm{NM})$

- Question d: Is the average germination rate before FM different from the average mean before NM? (Contrast c4: bFM-bNM).

We notice that contrast $\mathrm{c} 4$ is not orthogonal to the others. This means that its value depends on the values of the others. As a consequence, the contrast 4 will have to be entered in the ANOVA separately from contrasts $\mathrm{c} 1$ to $\mathrm{c} 3$, for which the effect of each single one is not depending on the others.

\subsection{Analysis of Variance for Testing the Contrasts}

The statistical analysis has been performed including the calculation of $\boldsymbol{R}^{2}$ (R-squared), which represents the coefficient of determination. $R^{2}$ is expressed as the ratio of the explained variance (variance of the model's predictions) to the total variance (sample variance of the dependent variable). In other words, it indicates the proportion of total variation of outcomes explained by the explanatory variables included in the model. In our case, we adopted the option "adjusted R-squared", which takes into account the number of degrees of freedom of the explanatory variables. For the ANOVA, two presentation options were used. The classical approach with the F test, but not showing the R-squared values was used for the overall analysis of variance (above). A second one, showing the R-squared, but operating on the basis of the calculated t-value (instead of the F-value) for the individual contrasts was chosen. In the case of orthogonal explanatory terms with one degree of freedom the $t$ test is equivalent to the $\mathrm{F}$ test $\left(\mathrm{t}^{2}=\mathrm{F}\right)$.

\subsubsection{ANOVA With the Three Orthogonal Contrasts c1, c2 and c3}

The corresponding statistical output 2 is as follows:

\begin{tabular}{ccccc}
\hline & Estimate & Std. Error & $\mathrm{t}$ value & $\operatorname{Pr}(>|\mathrm{t}|)$ \\
\hline (Intercept) & 99.9943 & 0.2839 & 352.276 & $<2 \mathrm{e}-16^{* * *}$ \\
c1 & 0.6182 & 0.3278 & 1.886 & 0.0627 \\
c2 & 0.6803 & 0.3278 & 2.076 & $0.0410 *$ \\
c3 & -0.6788 & 0.3278 & -2.071 & $0.0414 *$
\end{tabular}

Residual standard error: 2.663 on 84 degrees of freedom.

Multiple R-squared: 0.1264, Adjusted R-squared: 0.0952.

F-statistics: 4.051 on 3 and 84 DF, p-value: $0.009668 * *$.

\subsubsection{ANOVA Including Only Contrast c4}

The corresponding statistical output 3 is as follows:

\begin{tabular}{ccccc}
\hline & Estimate & Std. Error & $\mathrm{t}$ value & $\operatorname{Pr}(>|\mathrm{t}|)$ \\
\hline (Intercept) & 99.9943 & 0.2917 & 342.838 & $<2 \mathrm{e}-16^{* * *}$ \\
$\mathrm{c} 4$ & 1.3136 & 0.5833 & 1.886 & $0.0269^{*}$ \\
\hline
\end{tabular}

Residual standard error: 2.736 on 86 degrees of freedom.

Multiple R-squared: 0.05568, Adjusted R-squared: 0.0447.

F-statistics: 5.071 on 1 and 86 DF, p-value: 0.02687 *. 


\subsection{Interpretation}

- Question a (contrast c1): The difference between the average germination rate before, at and after FM (= 100.59) and the average germination rate before, at and after NM (=99.35) shows a trend toward significance $(\mathrm{p}=0.06)$.

- Question b (contrast c2): The average germination rate of before and after FM (= 101.27) is significantly different from the germination rate at FM $(=99.23)(\mathrm{p}=0.04)$

- $\quad$ Question c (contrast c3): The average germination rate of before and after NM (=98.67) is significantly different from the germination at NM $(=100.71)$ with a risk of error of 0.04 .

- Question d (contrast c4): If contrast c4 (bFM =101.74, minus bNM =99.11) is entered in the ANOVA as the last one in addition to $\mathrm{c} 1-\mathrm{c} 3$, it does not improve the model. This means that after having taken into account the contrasts $\mathrm{c} 1$ to $\mathrm{c} 3$, contrast $\mathrm{c} 4$ does not make any additional contribution to the variation of the germination rate. On the other hand, if we analyse only the contribution of contrast $\mathrm{c} 4$, ignoring contrasts $\mathrm{c} 1$ to $\mathrm{c} 3$, its contribution to the variation of the germination rate is also significant $(\mathrm{p}=0.03)$.

Taken together in the first analysis, the orthogonal contrasts $\mathrm{c} 1, \mathrm{c} 2$ and $\mathrm{c} 3$ have a highly significant explanatory value ( $\mathrm{p}=0.009668$, or $\mathrm{p}<0.01$ ), contributing to explain $9.5 \%$ of the total variation in the germination rate of the tested Spruce seeds.

The second analysis reveals the effect of $\mathrm{c} 4$ taken separately: here, the significance is still given, but in a lesser extent $(\mathrm{p}=0.0269)$. With $4.5 \%$, its contribution to the global variation in germination rate is about half of the previous one.

Given that $\mathrm{c} 4$ is not orthogonal to the three others, the explanatory contributions must be considered separately; in this sense we cannot conclude that globally the effect of the Moon position explains $14 \%$ of the total variation. Nevertheless, the data show that $9.5 \%$ of the total variation can be explained by three Moon contrasts, the $90.5 \%$ remaining variation being due to other factors, like genetic variability, single seed size, or spatial position of the tested series in the respective germination device. The devices themselves can be excluded as variability factors, being used in parallel through the whole trial, the growth conditions being kept as regular as possible.

\section{Conclusion}

Be it tested with the help of orthogonal contrasts $\mathrm{c} 1$ to $\mathrm{c} 3$, or with the help of contrast $\mathrm{c} 4$ alone, which corresponds directly to Kolisko's sowing method: both statistical ways demonstrate a significant relevance of the factor "Moon phases".

In this sense, the question of the reality of lunar cycles in plant physiology in general, in germination processes of Spruce in particular, receives here an additional statistically-based answer. Kolisko's results find here a belated confirmation for a first-order forestry species. The present findings occur in a narrow range, but are similar to those concerning the germination behavior of Musizi, where an abrupt fall in initial growth for sowings on the day of the full moon was observed, compared to the sowings of 2 days before.

This statistical analysis of Rohmeder's data according to a modern standard methodology allows us to reconsider his negative conclusion and to rehabilitate the value of Lili Kolisko's work. From the methodological point of view, it must be stressed that a higher accuracy would have been obtained if the tests had been made over three years or more, repeating them during the same months.

\section{References}

Bagnoud, N. (1995). Rythmicités dans la germination et la croissance initiale de 4 essences ligneuses de la Zone Soudano-Sahélienne. Essai lunaison. Bern: Groupe de foresterie pour le développement, IER Sikasso, Mali / Intercoopération 1995.

Barlow, P. W., Mikulecky, M., \& Strestik, J. (2010). Tree-stem diameter fluctuates with the lunar tides and perhaps with geomagnetic activity. Protoplasma, 247(1-2), http://dx.doi.org/10.1007/s00709-010-0136-6

Beeson, C. F. C. (1946). The moon and plant growth. Nature, 158, 572-73. http://dx.doi.org/10.1038/158572a0

Broendegaard, V. J. (1985). Ethnobotany: Plants in traditions, history and popular medicine - Tree felling and moon phases: superstition or folk-visdom? (In German) In: Contributions to Ethnomedicine, Ethnobotany and Ethnozoology. Verl. Mensch und Leben, Berlin, Bd. 6, 82-92.

Brown, F., \& Chow, C. S. (1973). Lunar-correlated Variations in Water Uptake by Bean Seeds. Biol. Bull, 145, 265-78. http://dx.doi.org/10.2307/1540039 
Cole, I. B., \& Balik, M. J. (2010). Lunar Influence: Understanding Chemical Variation and Seasonal Impacts on Botanicals. American Botanical Council. HerbalGram, 85, 50-56.

Endres, K. P., \& Schad, W. (1997). Biologie des Mondes. Mondperiodik und Lebensrhythmen. Stuttgart, Leipzig: S. Hirzel Verlag.

Hauser, A. (1973). Rural rules. A Swiss collection with comments (In German). Zürich, München: Artemis Verlag.

Holzknecht, K. (2002). Elektrische Potentiale im Splintholz von Fichte und Zirbe im Zusammenhang mit Klima und Mondphasen. Universitaet Innsbruck, Naturwissenschaftliche Fakultaet, Institut für Botanik. PhD-Thesis G0443 Physiol.

Holzknecht, K., \& Zürcher, E. (2006). Tree stems and tides- A new approach and elements of reflexion. Schweiz. Z. Forstwes, 157(6), 185-90. http://dx.doi.org/10.3188/szf.2006.0185

Kolisko, L. (1927). Der Mond und das Pflanzenwachstum. In G.Wachsmuth (Hrsg). "Gäa- Sophia” Jahrbuch der naturwissenschaftlichen Sektion am Goetheanum. Dornach, Switzerland, Bd II, 358-79.

Kolisko, L. (1929). Der Mond und das Pflanzenwachstum. In G. Wachsmuth (Ed.). "Gäa- Sophia” Landwirtschaft. Dornach, Switzerland, Bd IV: 84-94.

Kolisko, L. (1934). Der Mond und das Pflanzenwachstum. Mitteilungen des Biologischen Institutes am Goetheanum. Dornach, Switzerlan; Nr.1: 19-21 und Nr.2: 17-24.

Kolisko, L. (1935). Der Mond und das Pflanzenwachstum. The moon and the plant growth (in German). Mitteilungen des Biologischen Institutes am Goetheanum. Dornach, Switzerland; Nr.3, 17-19 and Nr.4, 3-14.

Milton, W. J. (1974). Exogenous variations in plant (Zea mais) germination and growth in darkness and 'constant' temperature, modified by uniform daily rotations. Dissertation, Northwestern University, Evanston, Illinois.

Navi, P., \& Heger, F. (2005). Thermo-hydromechanical behavior of wood (In French). Lausanne, Switzerland: Presses polytechniques et universitaires romandes.

Piccardi, G. (1962). Chemical Basis of Medical Climatology. Springfield, IL: Charles Thomas Publishers.

Pollack, G. H. (2013). The Fourth Phase of Water: Beyond Solid, Liquid and Vapor. Seattle, WA: Ebner and Sons Publishers.

Popp, M. (1933). Hat der Mond einen Einfluss auf das Pflanzenwachstum? Z. Pflanzenernährung, Düngung, Bodenkunde, 11(4), 145-50. http://dx.doi.org/10.1002/jpln.19330121002

Rohmeder, E. (1938). Der Einfluss der Mondphasen auf die Keimung und erste Jugendentwicklung der Fichte. Forstwissenschaftliches Zentralblatt , 60, Jhrg, Heft 19, 593- 603, 634-46.

Skaar, C. (1988). Wood-Water Relations. Berlin, Heidelberg, New York, London, Paris, Tokyo: Springer Ed. http://dx.doi.org/10.1007/978-3-642-73683-4

Spiess, H. (1994). Chronobiologische Untersuchungen mit besonderer Berücksichtigung lunarer Rhythmen im biologische-dynamischen Pflanzenbau (2nd ed). Schriftenreihe des Institutes für Biologisch-Dynamische Forschung, Darmstadt.

Spruyt, E., Verbelen, J. P., \& De Greef, J. A. (1987). Expression of Circaseptan and Circannual Rhythmicity in the Imbibition of Dry Stored Bean Seeds. Plant Physiol, 84, 707-10. http://dx.doi.org/10.1104/pp.84.3.707

Zürcher, E. (1992). Rhythmicities in the Germination and Initial Growth of a Tropical Forest Tree Species (in French with a German summary). Schwei. Z. Forstwes, 143(12), 951-66.

Zürcher, E. (2000). Moon-Related Traditions in Forestry and Corresponding Phenomena in Tree Biology. (In German, English summary) Schweiz. Z. Forstwes, 151(11), 417-424. http://dx.doi.org/10.3188/szf.2000.0011

Zürcher, E. (2008). Les Plantes et la Lune - traditions et phénomènes. In F. Hallé (Ed.). Aux Origines des Plantes Des plantes anciennes à la botanique du XXIè siècle (pp. 388-411). Paris: Arthème Fayard.

Zürcher, E. (2011). Plants and the Moon - Traditions and Phenomena. American Botanical Council HerbalEGram, 8(4).

Zürcher, E., Cantiani, M. G., Sorbetti-Guerri, F., \& Michel, D. (1998). Tree stem diameters fluctuate with tide. Nature, 392, 665-66. http://dx.doi.org/10.1038/33570

Zürcher, E., \& Mandallaz, D. (2001). Lunar synodic Rhythm and Wood Properties: Traditions and Reality. In Isabelle Quentin (Ed.), L'arbre 2000. The Tree. (pp. 244- 50) 4th International Symposium on the Tree, 20-26 August, 2000. Montreal: Institut de recherche en biologie végétale / Montréal Botanical Garden 2001. 
Zürcher, E., Rogenmoser, C., Soleimany Kartalaei, A., \& Rambert, D. (2012). Reversible Variations in Some Wood Properties of Norway Spruce (Picea abies Karst.), Depending on the Tree Felling Date. In K. I. Nowak \& H. F. Strybel (Eds.), Spruce: Ecology, Management and Conservation (pp. 75-94). Hauppauge, New York: Nova Science Publishers.

Zürcher, E., Schlaepfer, R., Conedera, M., \& Giudici. F. (2010). Looking for differences in wood properties as a function of the felling date: lunar phase-correlated variations in the drying behavior of Norway Spruce (Picea abies Karst.) and Sweet Chestnut (Castanea sativa Mill.). TREES, 24, 31-41. http://dx.doi.org/10.1007/s00468-009-0376-2

\section{Copyrights}

Copyright for this article is retained by the author(s), with first publication rights granted to the journal.

This is an open-access article distributed under the terms and conditions of the Creative Commons Attribution license (http://creativecommons.org/licenses/by/3.0/). 